\title{
How can we provide true synchronization in synchronized NIPPV?
}

\author{
Kadir Şerafettin Tekgündüz ${ }^{1}$ (I)
}

Received: 23 January 2019 / Revised: 30 January 2019 / Accepted: 19 February 2019 / Published online: 26 February 2019

(C) Springer-Verlag GmbH Germany, part of Springer Nature 2019

\section{Dear Editor:}

I read with great interest the manuscript entitled "Work of breathing during HHHFNC and synchronized NIPPV following extubation" [2], in which the authors mention using SNIPPV in a protocol section. They state that synchronization was achieved via a flow sensor located at the "y" piece, just proximal to the nasal prongs [2]. The detection of breathing in neonates is indeed difficult if breathing signals are weak or are superimposed upon a leakage flow, and so in neonates, flow measurement requires additional techniques that are not commonly available in clinical settings when SNIPPV is used [5]. The currently available synchronization methods between the ventilator and the patient in SNIPPV include pneumatic capsules, pneumotachograph $[1,5]$, although synchronization should be obtained via a pneumotachograph when using a Giulia neonatal ventilator, as was the case in the present study [4].

Even if a flow sensor is used, synchrony between mechanical and spontaneous breath occurs only during inspiration, as the inspiratory times of the mechanical and spontaneous breaths may be different [3]. Particularly in extremely small preterm infants, inspiratory times can be very short, and it is not possible to provide synchronized ventilation for both inspiration and expiration $[1,5]$.

The authors state that the trigger level was set at $0.1 \mathrm{~L} / \mathrm{min}$ for all infants, which is a very low level of trigger sensitivity. Trigger sensitivity set to the lowest level can lead to autotriggering, and so there is a need to set the optimal level to avoid auto-triggering.

Communicated by Patrick Van Reempts

Kadir Șerafettin Tekgündüz

k.tekgunduz@yahoo.com.tr

1 Division of Neonatology, Ataturk University Medical Faculty, Erzurum, Turkey
In conclusion, I am not sure synchronization was truly achieved in the manuscript. That said, a Cochrane metaanalysis reported that NIPPV reduces incidences of extubation failure and also the need for re-intubation within $48 \mathrm{~h}$ to 1 week more effectively than NCPAP [3]. Thus, the results of the study [2] can be considered valuable also with regard to non-synchronized nasal intermittent positive pressure ventilation.

Publisher's note Springer Nature remains neutral with regard to jurisdictional claims in published maps and institutional affiliations.

\section{References}

1. Aghai ZH, Saslow JG, Nakhla T, Milcarek B, Hart J, LawryshPlunkett R, Stahl G, Habib RH, Pyon KH (2006 Sep) Synchronized nasal intermittent positive pressure ventilation (SNIPPV) decreases work of breathing (WOB) in premature infants with respiratory distress syndrome (RDS) compared to nasal continuous positive airway pressure (NCPAP). Pediatr Pulmonol 41(9): 875-881

2. Charles E, Hunt K, Rafferty GF, Peacock JL, Greenough A (2019) Work of breathing during HHHFNC and synchronised NIPPV following extubation. Eur J Pediatr 178(1):105-110. https://doi.org/10. 1007/s00431-018-3254-3

3. Donn SM, Sinha SK (2015) Assisted Ventilation and Its Complications. In: Fanaroff and Martin's Neonatal-Perinatal Medicine Textbook, vol 2, 10th edn. Elsevier, Philadelphia, p $1087-1113$

4. Lemyre B, Davis PG, De Paoli AG, Kirpalani H (2017 Feb 1) Nasal intermittent positive pressure ventilation (NIPPV) versus nasal continuous positive airway pressure (NCPAP) for preterm neonates after extubation. Cochrane Database Syst Rev 2:CD003212

5. Mahmoud RA, Roehr CC, Schmalisch G (2011) Current methods of non-invasive ventilatory support for neonates. Paediatr Respir Rev 12(3):196-205. https://doi.org/10.1016/j.prrv.2010.12.001 